\title{
Antibiotic resistance in Helicobacter pylori: Recent insights
}

\author{
D Weerasekara ${ }^{1}$, DMBT Dissanayake $^{2}$, GIDDAD Athukorala $^{2}$, MM Weerasekera $^{2}$, \\ SSN Fernando ${ }^{2}$
}

Sri Lankan Journal of Infectious Diseases 2014 Vol.4(1):2-8

DOI: http://dx.doi.org/10.4038/sljid.v4i1.5986

Key words: Helicobacter pylori, Antibiotic resistance, Clarithromycin

\begin{abstract}
The discovery that Helicobacter pylori (H. pylori) infection is the main cause of most gastro duodenal diseases has dramatically changed the management of these diseases. Antibiotics are the mainstay of treatment. However, prevalence of $H$. pylori antibiotic resistance is increasing worldwide, and is the main factor affecting the efficacy of current therapeutic regimens.

In Sri Lanka, although eradication therapy for $H$. pylori by antibiotics is commonly advocated, due to a lack of susceptibility data, it has not been possible to formulate suitable guidelines for clinical use.
\end{abstract}

\section{Introduction}

Helicobacter pylori (formerly known as Campylobacter pylori or pyloridis) was first isolated from humans in1982. ${ }^{1}$ The first isolation of H. pylori in pure culture and its association with gastritis and peptic ulcer disease led to the awarding of the Nobel Prize in Medicine in 2005 to Barry Marshall and Robin Warren, two physicians in Australia. It is a spiral shaped Gram negative bacterium that lives within the mucus layer overlying the stomach and duodenum. The outstanding biochemical characteristic of helicobacter is its rapid urease activity. All clinical isolates are known to be urease positive. ${ }^{2}$

The prevalence of $H$. pylori infection correlates with socio-economic status and is seen more in developing rather than developed countries. ${ }^{3}$ In Sri Lanka, the prevalence of $H$. pylori estimated by using histology, biopsy urease and PCR ranges from $9.7 \%$ to $70 \%{ }^{4,5}$. This extremely wide prevalence appears to be due to different types of tests used in different studies. The sensitivity and specificity of PCR has been found to be very high, but is considered an experimental tool as it is not standardized. ${ }^{6}$ The sensitivity of the biopsy urease test reduces with treatment. ${ }^{6} \mathrm{We}$ are currently carrying out a study to determine which test is superior in confirming the presence of H. pylori from patients with dyspeptic symptoms.

\footnotetext{
${ }^{1}$ Department of surgery, Faculty of Medical Sciences, University of Sri Jayewardenepura, Sri Lanka ${ }^{2}$ Department of Microbiology, Faculty of Medical Sciences, University of Sri Jayewardenepura, Sri Lanka Address for correspondence: Dr. G.I.D.D.A.D. Athukorala; Department of Microbiology, Faculty of Medical Sciences, University of Sri Jayewardenepura, Sri Lanka. Telephone No:+94718661304

Email-dushyanthieathukorala@yahoo.com
} 
Every exposure to $H$. pylori does not lead to persistent colonization, either due to lack of adaptation to the particular host ${ }^{7}$ or to use of antibiotics. ${ }^{8,9}$ After $H$. pylori acquisition, virtually all persons develop persistent colonization that lasts for life. ${ }^{2}$ Chronic diffuse superficial gastritis, gastric ulceration, gastric adenocarcinoma and gastric lymphoma are associated with chronic $H$. pylori colonization.

Eradication of H. pylori in individuals may be the best course of action in the prevention of the above diseases. However, patients who receive H. pylori eradication standard triple therapy [proton pump inhibitor (PPI), amoxicillin (AMOX) and clarithromycin (CLA)] often encounter eradication failure over their treatment period. ${ }^{10}$ Development of antibiotic resistant strains of $H$. pylori may be the main factor affecting efficacy of current therapeutic regimens.

Worldwide, H. pylori antibiotic resistance towards different antibiotics has increased. Such a phenomenon may affect therapeutic management in different countries. ${ }^{11}$ The prevalence of bacterial resistance varies in different geographic areas, and has been correlated with the consumption of antibiotics in the general population. ${ }^{12,13}$ Prevalence of antibiotic resistance in $H$. pylori in Sri Lanka is not known and published studies in this area are sparse.

\section{Current anti $H$. pylori regimens}

Eradication therapy of $H$. pylori infection consists of different regimens. The standard first line regimen is triple therapy with AMOX, CLA and PPI given for 7 to 14 days. ${ }^{14,15}$ In areas with a high prevalence of CLA resistance, first-line therapy containing dual therapy (PPI and AMOX for 5 days) followed by triple therapy with a PPI, CLA and tinidazole [or metronidazole (MET)] for 5 days has been used, which is termed as sequential regimen. ${ }^{16} \mathrm{~A}$ new regimen termed as concomitant therapy is a 4-drug regimen (PPI, CLA, AMOX, and MET) for 7 to 10 days, which is more simple than sequential therapy and is more suitable for patients in high endemic areas of dual resistance to CLA and MET. ${ }^{16}$ Further, a sequential-concomitant hybrid therapy (dualconcomitant) consisting a PPI and AMOX for 7 days followed by a PPI, AMOX, CLA and MET for 7 days has shown promising success rate in attempts to overcome dual resistance. ${ }^{17}$

Bismuth containing quadruple therapy with MET, tetracycline (TET) and bismuth with PPI for 10 to 14 days used as second-line and/or salvage therapy has shown good efficacy in multicenter studies. ${ }^{18}$ In patients who failed with first line CLA-based triple therapy, levofloxacin (LEV)based triple therapy (LEV, AMOX, and a PPI) has proven to be superior to quadruple therapy and had fewer side effects as salvage therapy in a meta-analysis. ${ }^{19}$

The optimal therapeutic regimen has not been defined for refractory $H$. pylori infection. In this situation, the Maastricht IV/Florence Consensus Report recommends that whenever possible, anti-H. pylori treatment should be guided by antimicrobial susceptibility testing. ${ }^{15}$ However, antimicrobial sensitivity data for patients who failed eradication therapy with second line regimens is still not widely available. A recent prospective study has shown that a 10-day quadruple therapy with LEV, AMOX, bismuth, and rabeprazole as third-line treatment is effective and safe. ${ }^{20}$ Quinolone therapy and rifabutin or furazolidone (FUR) based regimens are the other alternative candidates for third-line therapy. ${ }^{21-23}$ 


\section{Epidemiology of antibiotic resistance}

Published data has shown that the prevalence of antibiotic resistance appears to be partly determined by geographical factors. ${ }^{23}$ Singh et al in 2009 tested $68 \mathrm{H}$. pylori isolates from North India and determined that all isolates were resistant to MET, while $65 \%$ were resistant to AMOX and $4.7 \%$ were resistant to CLA. However, none of the isolates were found to be resistant to TET. $^{24}$ In yet another study in Calcutta, about $90 \%$ of strains were MET resistant. ${ }^{25}$ In China, increased resistance to CLA and MET was seen from 2000 to 2009 (from 12.8 to $23.8 \%$ and 12.8 to $56.6 \%$ respectively), while AMOX resistance decreased from $2.1 \%$ to $0.3 \%{ }^{26} \mathrm{~A}$ high resistance to MET has been also reported from Saudi Arabia. The rate of resistance to MET in 2008 was $69.5 \%$, while CLA resistance was $21 \%$ and no resistance to AMOX was seen. ${ }^{27}$

These findings support the idea that $H$. pylori gene pools differ regionally and emphasize the potential importance of studies of Indian and other non-Western $H$. pylori populations in developing a global understanding of this gastric pathogen and associated disease. ${ }^{25}$

In Europe, there were huge differences in antibiotic sensitivities between southern and northern countries. Higher resistance rates of CLA in adults were observed in southern European countries such as Spain where the rate of CLA resistance was $35.6 \%$ in patient isolates of $H$. pylori. ${ }^{17}$

CLA resistance was also seemingly common in the USA, ranging from 10-15\%, while MET resistance rates were $20-40 \%$ and resistance to AMOX appeared to be infrequent. ${ }^{15,20}$ Mendonca et al. (2000) analyzed 90 Brazilian dyspeptic patients and showed that resistance of $H$. pylori to CLA, MET, TET, AMOX and FUR was 7\%, 42\%, 7\%, 29\%, and 4\%, respectively. ${ }^{28}$ A metaanalysis reported that overall $\mathrm{H}$. pylori antibiotic resistance rates (31 studies from 1993 to 2009) for AMO, CLA, MET, TET, LEV and multidrug-based therapies had increased in different continents. ${ }^{11}$

The prevalence of antibiotic resistance in various regions appearsto be associated with the pattern of general use of antibiotics in the region. An example is the high resistance rates to CLA seen in countries where this antibiotic is widely administered as mono-therapy for respiratory infections while there is low resistance seen in countries with a low consumption of macrolides. ${ }^{29}$ Another factor which might account for these existing geographic differences in antibiotic resistances is the presence of different $H$. pylori strains in particular geographic areas. $^{30}$

\section{Antibiotic resistance mechanisms}

The main antibiotic resistance mechanism which leads to $H$. pylori eradication failures arepoint mutations on the bacterial chromosome that cause changes in each drug's site of action. Other mechanisms such as acquisition of foreign genes carried on mobile genetic elements can also play a role. ${ }^{31}$

The bacteriostatic activity of CLA depends on its capacity to inhibit protein synthesis by binding to the $50 \mathrm{~S}$ bacterial ribosomal subunit. Resistance to CLA is due to $23 \mathrm{~S}$ rRNA mutations which 
inhibit the binding between CLA and the ribosomal subunit dedicated to the specific antibiotic related protein synthesis. Furthermore, expressions of active drug efflux mechanisms also play an important role in resistance to CLA. ${ }^{32-35}$ Amoxicillin is a $\beta$-lactam antibiotic which acts by interfering with peptidoglycan synthesis. It blocks transporters involved in peptidoglycan synthesis named penicillin binding proteins (PBP). Production of $\beta$-lactamase, i.e. the main mechanism of penicillin resistance in other bacteria, does not play a role in AMOX resistance in H. pylori. ${ }^{36}$

Bactericidal activity of MET depends on the reduction of its nitro-groups in anionic radicals, nitroso-derivates and hydroxylamines which are able to damage the DNA-helicoidal structure. MET resistance in $H$. pylori is complex and is primarily associated with mutational inactivation of the redox-related genes $(f r x A, r d x A)$. Different mutations involving the $r d x A$ gene which encodes for an oxygen insensitive NADPH nitro-reductase are recognized as the main mechanism conferring MET resistance in $H$. pylori. ${ }^{37}$ Meanwhile, there are reports that the MET resistance phenotype may arise in $H$. pylori without mutations in $r d x A$ or frxA, suggesting the presence of additional MET resistance mechanisms. ${ }^{38}$

Fluoroquinolones (FLU) exert a dose-dependent bactericidal effect by binding the sub-unit A of DNA gyrase (topoisomerase II), an essential enzyme for the maintenance of DNA helicoidal structure. The mechanism of FLU resistance in $H$. pylori has been found to be linked to mutations in the quinolone resistance-determining regions of the gyrase A ( gyrA) gene..$^{39,40}$ Mutations in the gyrase B $(g y r B)$ gene have also been identified in LEV resistant strains. However, this rarely occurs and is often associated with $g y r A$ mutations. ${ }^{23}$

Tetracycline acts as a bacteriostatic agent by inhibiting codon anticodon link at the level of $30 \mathrm{~S}$ ribosomal subunit and blocking the attachment of aminoacyl-tRNA to the acceptor site. Mechanisms of resistance to TET are associated with de novo mutations in the 16S rRNA gene. ${ }^{41}$ Factors other than point mutations in the $30 \mathrm{~S}$ ribosomal subunit may contribute towards the development of TET resistance. Possible mechanisms are ribosomal protection, ${ }^{42}$ decreased membrane permeability and reduced intracellular accumulation due to a specific tetracycline efflux pump system. ${ }^{43}$

\section{Conclusion}

Worldwide $H$. pylori resistance towards different antibiotics used in current eradication regimens is increasing and may affect the therapeutic management of malignant and non-malignant gastro duodenal diseases associated with $H$. pylori colonization. Antibiotic sensitivity data from different regions of the world highlights the need for constant surveillance of $H$. pylori antibiotic resistance, so that tailoring therapy is possible in clinical practice. The prevalence of antibiotic resistance in $H$. pylori in Sri Lanka is not known and studies in this area are needed for a better approach to treatment with current and alternative antibiotic regimens.

\section{Conflict of Interests}

There is no conflict of interest to disclose for all authors. 


\section{References}

1. Marshall BJ. A history of the discovery of Campylobacter pylori. Chapter in Blaser MJ, ed., Campylobacter pylori gastritis and peptic ulcer disease, New York, Igaku-Shoin, 1989:7-23.

2. Mandel GL, Bennett JE. Mandell, Douglas and Bennett's Principle and Practice of Infectious Diseases: Churchill Livingstone 2010.

3. Taylor DN, Blaser MJ. The epidemiology of Helicobacter pylori infection. Epidemiol rev. 1991; 13:42-59. No doi.

4. Fernando N, Holton J, Vaira D, et al. Prevalence of Helicobacter pylori in Sri Lanka as determined by PCR. J Clin Microbiol. 2002; 40(7):2675-6.

doi : http://dx.doi.org/10.1128/JCM.40.7.2675-2676.2002.

5. Wijetunge S, Halahakoon VC, Galketiya KB, et al. Detection of Helicobacter pylori by histology in biopsy specimens of patients with gastric ulcers in a selected group of patients from Teaching Hospital, Peradeniya. Proceedings of the Peradeniya University Research Sessions, Sri Lanka. 2011. pp 106. No doi .

6. Hunt RH, Xiao SD, Megraud F, et al. Helicobacter pylori in developing countries. World Gastroenterology Organisation Global Guideline. J Gastrointestin Liver Dis. 2011; 20(3):299-304. No doi.

7. Kang J, Blaser MJ. Bacterial populations as perfect gases: genomic integrity and diversification tensions in Helicobacter pylori. Nat rev Microbiol. 2006; 4(11) 826-836. doi: 10.1038/nrmicro1528.

8. Blaser MJ. Helicobacters are indigenous to the human stomach:duodenal ulceration is due to changes in gastric microecology in the modern era. Gut. 1998; 43:721-727. doi:10.1136/gut.43.5.721.

9. Mendall MA, Goggin PM, Molineaux N, et al. Childhood living conditions and Helicobacter pylori seropositivity in adult life. Lancet. 1992; 339(8798):896-897. doi : http://dx.doi.org/10.1016/0140-6736(92)90931-R.

10. Vakil N, Megraud F. Eradication therapy for Helicobacter pylori. Gastroenterology. 2007; 133(3):985-1001. doi : http://dx.doi.org/10.1053/j.gastro.2007.07.008.

11. De Francesco V, Giorgio F, Hassan C, et al. Worldwide H. pylori antibiotic resistance: a systematic review. J Gastrointestin Liver Dis. 2010; 19(4):409-414. No doi.

12. Boyanova L, Mitov I. Geographic map and evolution of primary Helicobacter pylori resistance to antibacterial agents. Expert revAnti Infect Ther. 2010; 8(1):59-70.

doi:10.1586/eri.09.113.

13. Megraud F. $H$ pylori antibiotic resistance: prevalence, importance, and advances in testing. Gut. 2004; 53(9):1374-1384. doi:10.1136/gut.2003.022111.

14. Chuah SK, Tsay FW, Hsu PI, et al. A new look at anti-Helicobacter pylori therapy. World J Gastroenterol 2011; 17(35):3971-3975. doi: 10.3748/wjg.v17.i35.3971.

15. Malfertheiner P, Megraud F, O'Morain CA, et al. Management of Helicobacter pylori infection--the Maastricht IV/ Florence Consensus Report. Gut. 2012; 61(5):646-664. doi: 10.1136/gutjnl-2012-302084.

16. Wu DC, Hsu PI, Wu JY, et al. Sequential and concomitant therapy with four drugs is equally effective for eradication of $H$ pylori infection.. Clin Gastroenterol Hepatol. 2010; 8(1):36-41. doi: 10.1016/j.cgh.2009.09.030.

17. Hsu PI, Wu DC, Wu JY, et al. Modified sequential Helicobacter pylori therapy: proton pump inhibitor and amoxicillin for 14 days with clarithromycin and metronidazole added 
as a quadruple (hybrid) therapy for the final 7 days. Helicobacter. 2011; 16(2):139-145. doi: 10.1111/j.1523-5378.2011.00828.x.

18. O'Morain C, Borody T, Farley A, et al. Efficacy and safety of single-triple capsules of bismuth biskalcitrate, metronidazole and tetracycline, given with omeprazole, for the eradication of Helicobacter pylori: an international multicentre study. Aliment Pharmacol Ther. 2003; 17(3):415-420. doi: 10.1046/j.1365-2036.2003.01434.x.

19. Liou JM, Lin JT, Chang CY, et al. Levofloxacin-based and clarithromycin-based triple therapies as first-line and second-line treatments for Helicobacter pylori infection: a randomised comparative trial with crossover design. Gut. 2010; 59(5):572-578. doi: 10.1136/gut.2009.198309.

20. Hsu PI, Wu DC, Chen A, et al. Quadruple rescue therapy for Helicobacter pylori infection after two treatment failures. Eur J Clin Invest. 2008; 38(6):404-409. doi: 10.1111/j.1365-2362.2008.01951.x.

21. Nishizawa T, Suzuki H, Hibi T. Quinolone-based third-line therapy for Helicobacter pylori eradication. J Clin Biochem Nutr. 2009; 44(2):119-124. doi: 10.3164/jcbn.08-220R

22. Poorten DVD, Katelaris PH. The effectiveness of rifabutin triple therapy for patients with difficult-to-eradicate Helicobacter pylori in clinical practice. Aliment Pharmacol Ther. 2007; 26(11):1537-1542. doi:10.1111/j.1365-2036.2007.03531.x.

23. Wenming Wu, Yunsheng Yang, and Gang Sun, "Recent insights into antibiotic resistance in Helicobacter pylori eradication," Gastroenterol Res Pract, 2012; . doi:10.1155/2012/723183.

24. Singh V, Mishra S, Maurya P, et al. Drug resistance pattern and clonality in $H$. pylori strains. J Infect Dev Ctries. 2009; 3(2):130-136. doi:10.3855/jidc.60.

25. Mukhopadhyay AK, Kersulyte D, Jeong JY, et al. Distinctiveness of genotypes of Helicobacter pylori in Calcutta, India. J Bacteriology. 2000; 182(11):3219-3227. doi: http://dx.doi.org/10.1128/JB.182.11.3219-3227.2000

26. Gao W, Cheng H, Hu F, et al. The evolution of Helicobacter pylori antibiotics resistance over 10 years in Beijing, China. Helicobacter. 2010;15(5):460-466. doi: 10.1111/j.1523-5378.2010.00788.x.

27. Marie MAM. Patterns of Helicobacter pylori resistance to metronidazole, clarithormycin and amoxicillin in Saudi Arabia. Journal of Bacteriology and Virology. 2008; 38(4):173178. doi: 10.4167/jbv.2008.38.4.173

28. Mendonça S, Ecclissato C, Sartori MS, et al. Prevalence of Helicobacter pylori resistance to metronidazole, clarithromycin, amoxicillin, tetracycline, and furazolidone in Brazil. Helicobacter. 2000; 5(2):79-83. doi : http://dx.doi.org/10.1046/j.1523-5378.2000.00011.x

29. Perez Aldana L, Kato M, Nakagawa S, et al. The relationship between consumption of antimicrobial agents and the prevalence of primary Helicobacter pylori resistance. Helicobacter. 2002; 7(5):306-309. doi : http://dx.doi.org/10.1046/j.1523-5378.2002.00096.x

30. Yamaoka Y, Kato M, Asaka M. Geographic differences in gastric cancer incidence can be explained by differences between Helicobacter pylori strains Internal Medicine. 2008; 47(12):1077-1083. no doi

31. Falush D, Kraft C, Taylor NS. Recombination andmutation during long-term gastric colonization by Helicobacter pylori: estimates of clock rates, recombination size, and minimal age Proceedings of the National Academy of Sciences of the United States of America. 2001; 98(26):15056-15061. doi: 10.1073/pnas.251396098

32. Torres-Debat ME, Perez-Perez G, Olivares A, et al. Antimicrobial susceptibility of Helicobacter pylori and mechanisms of clarithromycin resistance in strains isolated from 
patients in Uruguay. Revista espanola de enfermedades digestivas : 2009;101(11):757762. ISSN = 1130-0108; $/ \mathrm{a}$

33. Chen S, Li Y, Yu C. Oligonucleotide microarray: a newrapid method for screening the 23S rRNA gene of Helicobacter pylori for single nucleotide polymorphisms associated with clarithromycin resistance Journal of Gastroenterology and Hepatology. 2008; 23(1):126-131. doi: 10.1111/j.1440-1746.2007.04900.x

34. Hirata K, Suzuki H, Nishizawa T, et al. Contribution of efflux pumps to clarithromycin resistance in Helicobacter pylori. Journal of Gastroenterology and Hepatology. 2010; 25 Suppl 1:S75-79. doi: 10.1111/j.1440-1746.2009.06220.x.

35. Webber MA, Piddock LJV. The importance of efflux pumps in bacterial antibiotic resistance. Journal of Antimicrobial Chemother. 2003; 51(1):9-11.

doi: 10.1093/jac/dkg050.

36. Dore MP, Graham DY, Sepulveda AR. Different penicillin-binding protein profiles in amoxicillin-resistant Helicobacter pylori. Helicobacter. 1999; 4(3):154-161.

doi : http://dx.doi.org/10.1046/j.1523-5378.1999.99310.x.

37. Goodwin A, Kersulyte D, Sisson G, et al. Metronidazole resistance in Helicobacter pylori is due to null mutations in a gene ( $\mathrm{rdxA}$ ) that encodes an oxygen-insensitive NADPH nitroreductase. Mol Microbiol Immunol. 1998; 28(2):383-393. doi: 10.1046/j.1365-2958.1998.00806.x.

38. Bereswill S, Krainick C, Stahler F, et al. Analysis of the rdxA gene in high-level metronidazole-resistant clinical isolates confirms a limited use of $\mathrm{rdxA}$ mutations as a marker for prediction of metronidazole resistance in Helicobacter pylori. FEMS Immunol Med Microbiol. 2003; 36(3):193-198. doi: 10.1016/S0928-8244(03)00031-2.

39. Tankovic J, Lascols C, Sculo Q, et al. Single and double mutations in gyrA but not in gyrB are associated with low- and high-level fluoroquinolone resistance in Helicobacter pylori. Antimicrob Agents Chemother. 2003; 47(12):3942-3944.

doi: 10.1128/AAC.47.12.3942-3944.2003.

40. Chung JW, Lee GH, Jeong JY, et al. Resistance of Helicobacter pylori strains to antibiotics in Korea with a focus on fluoroquinolone resistance. J Gastroenterol Hepatol. 2012; 27(3):493-497 doi: 10.1111/j.1440-1746.2011.06874.x.

41. Ribeiro ML, Gerrits MM, Benvengo YH, et al. Detection of high-level tetracycline resistance in clinical isolates of Helicobacter pylori using PCR-RFLP. FEMS Immunol Med Microbiol. 2004; 40(1):57-61. doi: 10.1016/S0928-8244(03)00277-3.

42. Trieber CA, Burkhardt N, Nierhaus $\mathrm{KH}$, et al. Ribosomal protection from tetracycline mediated by $\operatorname{Tet}(\mathrm{O}): \operatorname{Tet}(\mathrm{O})$ interaction with ribosomes is GTP-dependent. . Biol Chem. 1998; 379:847-855. No doi.

43. Wu JY, Kim JJ, Reddy R, et al.Tetracycline-resistant clinical Helicobacter pylori isolates with and without mutations in $16 \mathrm{~S}$ rRNA-encoding genes. Antimicrob Agents Chemother. 2005; 49:578-583. doi : http://dx.doi.org/10.1128/AAC.49.2.578-583.2005. 